\title{
Teacher Professional Collaboration in China: Practices and Issues
}

\author{
Peng Liu \\ Assistant Professor, Faculty of Education, University of Manitoba, \\ Canada - Corresponding author \\ peng.liu@umanitoba.ca \\ QiXiu \\ Faculty of Education, The University of Hong Kong, China
}

\begin{abstract}
Fostering higher-order thinking skills of students is important aim for 21st century education. Teachers, as important elements in a positive learning environment, are the key to high quality education. As for the importance of teacher professional collaboration in teacher development, Hargreaves and Fullan (2012) pointed out that teachers' professional collaboration will benefit not only students but also the whole school community, and even society at large. In Chinese context, the Ministry of Education of the People's Republic of China (2010) issued a policy in 2010 promoting teacher professional collaboration and development as a background of this study, implying that teachers must be collaborating actively with colleagues in daily professional life to achieve collective growth for the purpose of improving student learning.

Based on the policy reality, this study explored teacher professional collaboration in the Chinese education context. It looked in particular at practices and issues in teacher professional collaboration. This article begins with the definitions of teacher professional collaboration, followed by a detailed exploration of this type of collaboration in Chinese education and issues related to its implementation. This study will provide holistic picture of teacher collaboration in China for contributing to theoretical development and educational practice.
\end{abstract}

\section{Keywords}

teacher professional collaboration - China 


\section{Teacher Professional Collaboration in the International} Literature

Teacher collaboration has been explored in different disciplines. In 1932, a researcher in the social sciences examined the problem of non-cooperation within teacher teams (Waller, 1932). The point of view of this analysis was primarily sociological. This marked the starting point of the study of teacher professional collaboration. Over the years, different terminology has been used in the teacher collaboration literature including teacher collaboration, teacher professional communities, and community of practice. These terms have been used interchangeably in the studies on teacher collaboration (Vangrieken, Dochy, Raes, \& Kyndt, 2015). Professional collaboration between teacher colleagues is an important route to teacher development. It is influenced by many factors including value orientations, psychological preferences, age, gender, knowledge and ability, teachers' attitudes towards and motivation for professional development, the physical, cultural, and institutional environment of the school (Deng, 2008), and uncertainties and the lack of a common culture in the teaching profession (Guo, 2007). A comprehensive analysis of these influential factors will be of great significance in guiding appropriate reform measures in practice.

According to Vangrieken et al.'s (2015) review, different forms of teacher collaboration exist in educational practice. Little (1990) categorized four forms of teacher collaboration, which include scanning for ideas and story-telling, sharing, assistance or aid, and joint-work.

The alternative terms professional community or professional learning community have both been used with the same meaning in the literature. Van Maanen and Barley (1984) described a professional community as a group of people collaborating and engaging in common work, and sharing similar values and norms about teaching and learning. Additionally, Westheimer's (2008) review on the concept of teacher professional communities and its relationship with teaching learning theorized teacher colleagues as an important resource that could provide special context to teachers' learning (as cited in Vangrieken et al., 2015). Teachers collaborate through sharing ideas and values within their community, thereby transforming them into communities of practice (Chen, 2016; Eschler, 2016; Grossman, Wineburg, \& Woolworth, 2001) or teacher teams (Cohen \& Bauketm 1997; Wu, 2012). The literature has also described the community of practice as one category of teacher professional communities. It is one of the three key components of the concept of teacher community, with the others being the community of understanding and the community of affection (De Lima, 2001, as cited in Vangrieken et al., 2015). 
In1995, American educator Ernest Boyer formally proposed the concept of the learning community in the book Basic School:Learning Community. It is believed that the most effective and important element in schools is the establishment of a real learning community. He built his theory of the professional learning community on the concepts of "community" and "learning community". In 1997, Hord, while working at the Southwest Educational Development Laboratory, carried out a long-term, in-depth, and meticulous study of the theoretical and practical problems of professional learning communities, and established a corresponding theoretical system. Hord (1997) believed that a professional learning community is composed of teachers and management who believe themselves to be a team. They work together to promote student learning through mutual cooperation, joint research, and the continuous improvement of teaching practice. As more and more experts and scholars are participating in the study of professional learning communities, the interpretations of this term professional learning community are becoming more and more diverse.

Another version of teacher professional learning communities is learning circles (Hairon \& Dimmock, 2012; MOE, 2001). Dufour (2004) regarded the professional learning community as "focus[ed] on learning rather than teaching". Thomas (1998) pointed out that one significant turn in the study of teacher professional development is the change in focus from professional individualism to learning communities. She pointed out that teachers' knowledge of teaching can be enhanced through the practice of cooperation among teachers.

The construction of teachers' professional learning communities can promote teachers' professional development (Boyle \& While, 2004; Corcoran, 1995; Desimone, 2011; Garet et al. 2001; Liu \& Yang, 2017; Villegas-Reimers, 2003). Teachers shoulder the responsibility of cultivating high-level talent and helping students to gain the capacity to succeed in society. This requires teachers to maintain sustainable development, which can be achieved through lifelong learning and active learning to improve their knowledge and skills. Teacher professional development is a process of continuous learning and improvement. Teacher professional development runs throughout teachers' entire teaching career, is oriented towards teacher's growth, and relies on particular development agencies and cultural environments. Teaching knowledge and teaching ability can be constantly improved through advanced concepts of teachers' professional development and lifelong learning. These can also continuously consolidate teachers' professional knowledge, enhance their professional autonomy, constantly improve their ability in scientific research and self-reflection ability, and strengthen their occupational moral. These advantages all contribute to the dynamic process of the development and maturity of teachers' professionalism ( $\mathrm{Li}, 2011)$. 
Scholars in Chinese context have specified three reasons for understanding the initiative to promote teacher professional collaboration (Zhang \& Zhang, 2011). First, there is a lack of teacher collaboration in China, which has been a concern for teachers, educators, school administrators, and society at large. Second, it is recognized that teacher collaboration contributes to the sharing of experience and facilitates the creation of mutual benefits among teachers. Third, the recent education reform requires effective teacher collaboration; this differs from the focus on individualism in previous educational reforms (Zhang \& Zhang, 2011).

The definitions of teacher collaboration in the Chinese literature are diverse (Chen, 2012; Deng, 2007; Lu, 2007; Zhang \& Zhang, 2011). Scholars in this area have used many different terms such as teacher professional collaboration, professional learning community, and teacher professional development (Chen, 2012; Guo, 2007; Lu, 2007; Zhang, 2014; Zhang \& Peng, 2012). The different definitions all represent the essential element that is collaboration, although the definition of teacher professional development is comparatively general with other definitions.

In 1982, teacher professional community was first used in a Chinese academic article (Shen, 2015). Shen (2015) argued that the teacher professional community differed from a teacher professional team since the latter did not have specific aims in the teaching field. On the other hand, the teacher education community focused on the spiritual aspect of a teacher community. A community of cooperation and a community of practice have also been implemented in the form of collaboration between primary and secondary schools in Chinese education context (Zhang \& Peng, 2012). In each collaboration project, teachers built collaborative bonds through research, internship, and further studies in their schools (Zhang \& Zhao, 2012). Lu (2007) stated that the essence of education was the cooperative enterprise while teaching was the collaborative profession. $\mathrm{Lu}(2007)$ believed that teachers' professional collaboration means the collaborative activities that take place between teachers and their team for promoting the quality of teaching. Usually, the activities include working separately and researching together for collaborative resource sharing and learning. Accordingly, teacher professional collaboration entails interactive relationships in which teachers promote their teaching practice through voluntary, equalitarian, and mutually engaging discussion and problem solving (Deng, 2007). This line of practice describes the forms of teacher collaboration in practice. However, the quality, process and effects of teacher collaboration in school improvement process needs further exploration. 
The research on professional learning communities has been carried out recently, but professional learning communities have not been fully implemented in China. However, their usage has been noticed and studied by some scholars (Lee \& Sharicz, 2014; Sargent \& Hannum, 2009; Wang, 2014, Yang, 2013). Yang (2013) believes that the cooperation in teachers' professional learning communities should aim at strengthening students' learning and collaborative work, creating and sharing learning opportunities and achievements, and maintaining and promoting instructional practice and the learning organization for teachers. Although this definition of professional learning communities differs from other previous definitions, most scholars believe that cooperative learning activities form the core of professional learning communities, and the ultimate goal of such communities is to promote student learning and development.

\section{3 Forms of Teacher Collaboration in Chinese Education Practice}

Different forms of teacher collaboration exist in Chinese educational practice. Teacher collaboration can be organized within schools, across schools, or across regions (Lu, 2007). It can be implemented as "peer teaching" within a school or an "expert teacher" serving a number of schools (Lu, 2007). In summary, the following are the common forms of teacher collaboration in Chinese schools: teaching-research groups (jiaoyan $z u$ ), lesson preparation groups (beike zu), expert teachers' workshops, masters' workshop, experts stationed in schools, inter-school cooperation, and student teacher practice in local schools (Li \& Li, 2014; Tan, 2013; Wang, 2014). These forms of teacher collaboration all contribute to teacher professional development in different ways, but in practices issues also come along with these forms.

Teacher Collaboration at the Team Level in China

Traditionally, teacher collaboration involves a group of teachers meeting to discuss pedagogical design or instructional improvement. However, a collaborative team of teachers is more than a group of people who meet periodically (DuFour \& Eaker, 2010). In the Chinese education field, a collaborative team is a group of teachers working interdependently to achieve common goals.

Chinese teacher collaboration at the team level generally has two forms: 1 . teaching teams made up of teachers who work in the same school and teach the same subject; 2 . teaching team consisting of teachers from different schools who teach the same subject (Liu, 2011). Many activities are conducted in teams including mentoring, peer coaching, team teaching, collaborative scientific research, 
and collective lesson preparation (Yu, 2007). It is common to see English, math, or science teachers collaborating as a team with other teachers of the same subject in their school. For example, English teaching in China is very common in primary and secondary schools. English teachers form teams so that they can cooperate on collective development to ensure their instructional effectiveness, which were followed by creating a culture of teamwork among teachers, establishing a good team atmosphere, and cultivating teachers' ability to practice collaboration. Lin (2013) used surveys and questionnaires to investigate collaboration in mathematic teaching. The survey found that elementary school mathematics teachers' cooperative activities included collective lesson preparation and evaluation $(73.9 \%)$, educational research group activities $(53.9 \%)$, mentoring and teaching $(53.1 \%)$, class cooperative management $(39.2 \%)$ and its related research $(21.8 \%)$, case discussion $(16.9 \%)$, cooperative teaching projects $(9.4 \%)$, and curriculum development (7.2\%). Within-school single subject teacher collaboration teams are very common in Chinese education for promoting teaching quality and improving administrative management. This form of teacher collaboration at the team level is the most basic teacher collaboration organization. It has been providing the common space for teachers to learn from each other, but on the other hand, there are also problems in the operation of teacher team including miscommunication, internal conflicts, and political factions.

Teacher collaboration teams consisting of teachers from different schools who teach the same subject generally are made up of senior teachers and novice teachers $(\mathrm{Wu}, 2012)$. Improving junior teachers' teaching capabilities and enriching their professional knowledge is the main focus of this form of collaboration. This is relatively new form of teacher collaboration in Chinese education context, particularly in the process of turnaround school transformation. This allows turnaround schools to have quality teacher resources from quality schools, which facilitates the teacher mobility. Expert teacher workshops are one of the most important forms of teacher collaboration in this category $(\mathrm{He}, 2013)$. Expert teacher workshops are chaired by a very experienced teacher, and provide networking platforms and diverse training activities in order to improve teachers' professional capabilities. Expert teacher workshops not only contribute to the developments of their members professionally, they also effectively build the team culture of learning across schools. The diversity of expert teacher workshops relies on the instructional and research interests of teachers who would like to participate in this form of teacher collaboration. Advantages of expert teacher workshop include appropriately taking advantages of quality teaching resources from key schools, reducing imbalanced development cross schools, and benefiting the turnaround school development. Disadvantages also include "administrationalization" of teacher professional 
development, meaning that the enrolling expert teacher workshop member relying on the arrangement of education administration instead of the initiation of expert teacher.

Teacher collaboration across the education sectors in China mainly refers to collaboration between university teachers and primary and secondary school teachers for facilitating teacher education at the university level (Chen, 2016).

Collaboration between schools and universities (S-U) is an effective teacher collaboration strategy for teacher education. It is aimed at facilitating pre- and in-service teachers' professional development and enhancing the quality of teacher education. This kind of partnership is called the "S-U model" (Chen, 2016). Chen(2016) showed that "S-U" cooperation is an effective approach to the integration of teachers' pre- and in-service education and is the best choice for connecting educational theory with practice. S-U cooperation has integrated the advantages of the higher education institutes, secondary schools, and local education administrative departments in the university and primary and secondary school context (Dong, Liu, \& Hang, 2012).

Dong et al. (2012) further proposed the "U-G-S" model. This refers to normal universities, local governments, primary and secondary schools carrying out pre-service training, induction education and on-the-job training. Educators across education sectors collaborate with others in team teaching and work conjointly with other individuals, school administration, and parents to bring about positive outcomes.

Collaboration between universities and the teaching research section in local schools provides opportunities for teachers in training to get practical teaching experience (Li, 2016; Wu, 2012; Zhang \& Peng, 2012; Zhou, Liang, \& Wang, 2016). On the one hand, these new teachers can get access to local schools and practice teaching in classrooms. On the other hand, universities can provide teaching methods for new teachers and researchers can get the opportunity to conduct research in local schools.

Generally speaking, there are some commonalities between universities and primary and secondary schools. For example, both are educational organizations focusing on cultivating talents. However, universities and primary and secondary schools have shown remarkable differences in specific educational practices (Zhang \& Peng, 2012), including professional lifestyle, school culture, and the type of knowledge transferred. As for the professional lifestyle of teachers, university teachers are more likely to have independent professional development; from their professional training programs to the arrangement 
of their teaching hours and classroom locations, from the creation of their teaching materials to their choice of teaching methods, college teachers have rights and autonomy in their classroom teaching. However, primary and secondary school teachers have less control in this regard. The professional lives of teachers in primary and secondary schools are often influenced by external pressures or instructions, and there is a lack of unity among teachers and autonomy in these teachers' instructional practices (Zhang \& Peng, 2012).

As for school cultural characteristics, the university is more inclined to an academic culture with rational thinking, inquiry-style questioning, and the promotion of systematic theories and logical completeness, whereas primary and secondary schools' culture tends to focus on obedience at the expense of solution-seeking (Zhang \& Peng, 2012). In terms of the type of knowledge emphasized in the institutions at these two levels, due to the above-mentioned differences in learning and work conditions, university teachers tend to have stronger analytical skills than primary and secondary school teachers. These differences mean that universities, and primary and secondary schools, have unique advantages and shortcomings.

The purpose of teacher education across institutions in China is to foster the future teachers in the following ways: First, teachers should be encouraged to participate in continuing education and training to enhance their educational literacy. Second, teachers from different schools should have the opportunity to work on joint cooperative and participatory research projects. In order to participate in research conducted by university teachers, primary and secondary school teachers can become directly involved in the university personnel training process, and obtain mentors directly from the university (Zhang \& Peng, 2012).

To facilitate primary and secondary education reform, new forms of teacher collaboration between university and primary and secondary school teachers have been established. For instance, Ye et al. (2017) summarized the "PET model" for professional collaboration between professors, experts, and teachers. It facilitates teacher professional development in different contexts, including among colleagues, and between universities and primary and secondary schools (Ye \& Si, 2017). This type of collaboration can include a number of professional development activities, such as "inviting teaching experts from primary and secondary schools to universities to assist the professional growth of pre-service teachers", "going out" (in which university professors give support to teachers in primary and secondary schools), and organizing "Same Lesson, Different Scaffold" sessions (in which teaching behaviors in primary and secondary schools are recorded and analyzed).

This kind of project-based professional collaboration also faces challenges. For example, it has been found that some primary and secondary school teachers 
lack the motivation to collaborate and seldom have time to touch upon professional development problems. Some teachers even lack enthusiasm and initiative in teaching.

\section{Teacher Collaboration across Regions}

In the Chinese education field, collaboration across regions refers to cooperation between counties, cities, provinces, and nations. Teacher professional collaboration across cities or provinces is normally based on teaching research projects ( $\mathrm{Li} \& \mathrm{Li}$, 2014). Wang (2016) mentioned a teacher collaboration project that stretched across four provinces in China. The cooperation of four regional teacher communities in Beijing, Jiangsu, Guangdong, and Zhejiang not only expanded the scope of cooperation between individual schools, but also allowed researchers to examine provincial culture which was not limited to a local area (Wang, 2016). In this study, the teachers from the four regions exchanged professional teaching experiences and collaborated with each other. The model of teacher professional collaboration that emerged in this project included elements such as multiple subjects, a common vision, shared decision-making, comprehensive content, efficient tools, etc. In this form of collaboration, creating an authentic environment and practice is essential to the community (Wang, 2016). Teachers can work together to solve problems in education practice (Zhu, 2014). When teachers in Wang's study prepared their teaching content, they needed to think and design better at different stages. For example, the math teaching was divided into four stages according to the characteristics of teaching in these four different regions. Afterwards, comprehensive teaching methods and pedagogy derived from the collaboration among these four regions were implemented, which improved the teaching and learning quality of the whole community (Wang, 2016).

Another example of teacher collaboration across regions is co-teaching in Sino-foreign cooperative education. This provides opportunities for teacher professional collaboration, such as developing a coursework team (Yu, 2007), peer observation $(\mathrm{Wu}, 2009)$, class curriculum assessment (Lin, 2013), participation in scientific research (Hu, 2012; Li, 2008; Li, 2016; Li, 2016; Liu, 2015; Wu, 2009; $\mathrm{Yu}$, 2007; Zhang \& Zhang, 2011), and building teacher professional communities (Xia, 2015). Zhu (2014) pointed out the chances for local teachers to cooperate with Chinese teachers abroad have increased in recent years, and in this process the teaching quality has been improved. This study concluded that preparation before class among teachers in different regions could reduce differences in teaching quality between teachers from various backgrounds and cultures (Zhu, 2014). 
The larger the scope of the teacher collaboration is, the more complicated a project can become (Hargreaves \& Fullan, 2012). Xin and Wang (2011) investigated teacher collaboration in China that aimed at raising not only the kindergarten admission rate, but also the quality of preschool education. Cooperation between a university and a kindergarten is the effective key approach according to the experience of the University-School Partnership Center of the Chinese University of Hong Kong, which is a successful example of a university-kindergarten partnership (Xin \& Wang, 2011). In this project, the organization of the teacher collaboration was professional both in its conceptual framework and in its practice. The conceptual framework was called " $3 \mathrm{R}-4 \mathrm{P}$ $5 \mathrm{E}$ ", which means reconceptualization, restructuring, re-culturing, problem clarification, planning, programme action, progress assessment, environment, experience, exploration, exploration, expression, and empowerment (Xin \& Wang, 2011). The project improved teachers' professional knowledge and the leadership capacity of the director and backbone teachers, in order to face the challenges of kindergarten education reform. Teachers who participated in this project acquired skills in self-evaluation, the ability to examine the overall learning environment, capacity in writing reports on their work within the kindergarten, and chances to put forward development plans, reflection and improvement measures, etc. (Xin \& Wang, 2011).

Several insights can be gained into the process of collaboration across regions. First, it is important for the cooperation to include three parties: schools in different areas, universities, and initiators. Collaboration was effective when all three parties worked together. However, sometimes, insufficient communication affects the quality of the collaboration. Second, the capacity for collaboration of each university education department needs to be improved. Third, the focus of the cooperation should be effectively transferred. Although the universities or experts in partnerships play a significant role, the other stakeholders should gradually strengthen their role in the organization in the course of developing the cooperative relations.

Existing Problems and Challenges in Chinese Teacher Collaboration

The main problems with teacher collaboration in China are limited awareness about teacher collaboration and limited willingness among teachers to cooperate. Competition and conflict of interests among individual teachers are common, which negates the development advantages brought about by cooperation (Littler \& Leverick \& Bruce, 1995; Lin, 2007; Niu, 2014). Five main behavioral problems in existing forms of teacher collaboration in China, 
which contributes to the above-mentioned problem. First, intercollegiate cooperation between teachers lacks of institutional guarantee. Other objective factors (such as distance) also hinder its development. Teachers also have a weak sense of cooperation (Cao, 2017; Lin, 2007; Niu, 2014). Second, single-disciplinary cooperation has narrowed teachers' scope of professional interaction. Teachers in China seldom communicate with teachers of other subjects. It is difficult for teachers in different disciplines to collaborate in practice(Cao, 2017; Lin, 2007). Third, multi-disciplinary cooperation may cause unexpected problems. Teachers in China have a strong sense of the curriculum system and its integrity. A lack of necessary communication and cooperation between them could cause unexpected problems when implementing multi-disciplinary cooperation (Cao, 2017; Lin, 2007; Niu, 2014). Fourth, the scope of cooperative teaching methods in China is limited to preschool education only. Finally, collaboration in teaching-research groups has become a mere formality. These group research tasks often do not lend themselves to cooperation and the research activities also often lack effectiveness. This is because teachers' energy is limit and their teaching load is often heavy. Manipulation and bureaucratic issues within the organization can also hinder teachers from achieving the real purpose of collaboration research (Cao, 2017; Lin, 2007; Niu, 2014; Wen \& Ren, 2010; Wang, 2013; Wei, 2014).

Additionally, the current evaluation system for teacher development is often based in competition. This evaluation method is relatively singledimensioned, focusing on only the appraisal of various aspects of teaching performance on a rigid index. Teachers' cooperative achievements are not regarded as an important evaluation index; there is a lack of systematic, holistic, personalized, and targeted assessment of teachers' cooperation. Because teacher collaboration is not evaluated, it remains at the surface level. This greatly hinders teachers from realizing of the function and effectiveness of collaboration. The problems with teacher collaboration have arisen from the interactions of various factors. Internal factors, such as traditional Chinese culture and the social environment of the market economy, and external characteristics of the teaching profession in China may create challenges for existing teacher collaborations and provide an unclear path for future teacher collaboration (Lin, 2007).

8 Conclusion

Many types of research have been conducted from different perspectives on different forms of teacher collaboration in China. This article explored teacher 
collaboration in China at three levels: teacher collaboration within schools, across schools, and across different areas. It also explored the definitions of teacher collaboration. The essence of teacher collaboration is for teachers to work together to solve a generic problem (Zhang \& Zhang, 2011). The above discussion outlines the general rationale for and structure of teacher cooperation in China, and provides a clearer development path or direction for future teachers' cooperation.

Diverse issues exist in Chinese teachers' collaboration. Many are related to the lack of a clear understanding of collaboration in Chinese educational organizations. This lack of understanding can be understood through the lens of China's unique culture and values. Problems such as the organizational and procedural weakness of collaborations can be attributed to difficulties in managing teacher teams. Non-cooperation between different school levels can be attributed to unequal information and mismanagement of the school teaching faculty.

This article also identified different forms of collaboration. At the team level, grade and cross-grade level collaborations are organized within a school. Teachers who teach the same subject can collaborate more easily and more intensely. On the other hand, the teacher research group is another form of teacher collaboration in schools, through which teachers work together to conduct particular research projects relevant to teaching practices. Additionally, in order to facilitate teacher professional development, university and school teacher collaboration is encouraged in the Chinese education context. At the cross-school level, the literature commonly identify teacher collaboration in teacher training and research-based projects. To increasing the effectiveness of their teaching, teachers in kindergartens, primary schools, secondary schools, and universities designed various kinds of teacher collaboration for novice teachers. For teachers in primary and secondary schools, a variety of collaboration models were implemented through the assistance of research. With the development of integrated interdisciplinary teaching, different levels of teachers can become willing to collaborate with each other and solve pedagogical problems collectively. In the Chinese literature, most teacher collaboration across provinces and countries was implemented through instructional research projects. Compared with the other forms of collaboration, this kind of teacher collaboration recruits more teachers, and the organization is more complicated. In another kind of collaboration, which focuses on improving instructional effectiveness, teachers are invited to get together and discuss their teaching subject, teaching styles, and even teaching mission. With the development of information technology, a broader scope of teacher collaboration can be achieved through the Internet. 
This study identified policy as the most prominent factor influencing teacher collaboration. In the Chinese context, due to the top-down administrative management structure in schools, policies on teacher collaboration are relatively easy to implement. However, individual factors such as age, sex, and educational qualifications also influence individual teachers' quality of teaching. Besides, a culture of teacher collaboration would result in different collaboration outcomes. Last, how to organize teacher collaboration is also a key factor, as an effective model of teacher collaboration could facilitate teacher professional development and improve the quality of teaching.

\section{References}

Boyer, E.L. (1995) The basic school: A community for learning. Princeton, NJ: The Carnegie.

Boyle, B., D. While, \& T. Boyle. (2004) A Longitudinal Study of Teacher Change: What Makes Professional Development Effective? The Curriculum Journal 15 (1), 45-68. 10.1080/1026716032000189471.

Cao, Q. (2017) The landscape of "Leading”. Junior High School Students World, (44), 10-12.

Chen, F. (2016). International Experience and Enlightenments on "S-U" Cooperation of Teacher Education: From the Perspective of Teacher Professional Development. Primary \& Secondary Schooling Abroad (2), 37-42. (in Chinese).

Chen, Y. (2012). Based on the practical survey of cooperation of teachers' professional development. Chinese Journal of Education (5), 84-87. (in Chinese).

Cohen, S.G., \& Bailey, D.E. (1997). What makes teams work: Group effectiveness research from the shop floor to the executive suite. Journal of Management, 23(3), 239-290.

Corcoran, T.B. (1995). Helping Teachers Teach Well: Transforming Professional Development. Brunswick, NJ: Policy Briefs, Consortium for Policy Research in Education.

Datnow, A. (2011). Collaboration and contrived collegiality: Revisiting Hargreaves in the age of accountability. Journal of Educational Change, 12(2), 147-158.

De Lima, J.Á. (2001). Forgetting about friendship: Using conflict in teacher communities as a catalyst for school change. Journal of Educational Change, 2(2), 97-122.

Deng, T. (2007). A review on the research of teachers professional collaboration in western countries. Studies in Foreign Education, 34(7), 14-18. (in Chinese).

Deng, T. (2008). An Exploration on Influential Factors of Teacher Professional Collaboration. Studies in Foreign Education, 35(12), 7-12. (in Chinese).

Desimone, L.M. (2011). A Primer on Effective Professional Development. Kappan 92 (6), 68-71. 10.1177/003172171109200616. 
Dong, Y., Liu, Y., \& Hang, G. (2012). U-G-S:Design and Implementation of Innovative Teacher Education Model. Journal of Northeast Normal University (Philosophy and Social Sciences) (6), 170-175. (in Chinese).

Dufour R. (2004). What is a professional learning community. Educational Leadership, (8), 6-11.

DuFour, R., \& Eaker, R. (2010). On common ground: The power of professional learning communities. Solution Tree Press.

Eschler, B.H. (2016). Finnish Teacher Collaboration: The Behaviors, Learning, and Formality of Teacher Collaboration. (Doctoral dissertation.). Brigham Young University, Provo, USA.

Garet, M.S., A.C. Porter, L. Desimone, B.F. Birman, \& S.Y. Kwang. (2001). What Makes Professional Development Effective? Results from a National Sample of Teacher. American Educational Research Journal 38 (4): 915-945. 10.3102/00028312038004915.

Grossman, P., Wineburg, S., \& Woolworth, S. (2001). Toward a theory of teacher community. The Teachers College Record, 103, 942-1012.

Guo, D. (2007). Mutual help and cooperation: Effective Strategy for the teacher professionalization development. Theory and Practice of Education, 27(11), 28-32. (in Chinese).

Hairon, S., \& C. Dimmock. (2012). Singapore Schools and Professional Learning Communities: Teacher Professional Development and School Leadership in an Asian Hierarchical System. Educational Review 64 (4): 405-424. 10.1080/00131911.2011 .625111 .

Hargreaves, A., \& Fullan, M. (2012). Professional capital: Transforming teaching in every school. New York: Teachers College Press.

He, C. (2013). The teacher collaboration in teacher studio. Shanghai Education Study (12), 57-58. (in Chinese).

Hord, S.M. (1997). Professional learning communities: Communities of continuous inquiry and improvement. Austin, Texas: $S E D L, 27$.

$\mathrm{Hu}, \mathrm{Y}$. (2012). Empirical study on the nature of teaching and research group in secondary schools in china: A case study of secondary schools in the urban area of Beijing. Journal of Education Studies, 8(6), 78-88. (in Chinese).

James, C., Dunning, G., Connolly, M., \& Elliott, T. (2007). Collaborative practice: a model of successful working in schools. Journal of Educational Administration, 45(5), 541-555.

Kelchtermans, G. (2006). Teacher collaboration and collegiality as workplace conditions. A review. Zeitschrift für Pädagogik, 52(2), 220-237.

Lee, P.M., \& A.A. Sharicz. (2014). The Unfolding of a Professional Learning Community. Pedagogy and the Human Sciences 1 (4), 39-50.

Li, D.W., \& Li, H.Y. (2014). The organization form and perfect strategy of teacher collaboration. Journal of Educational Institute of Jilin Province, 7(30), 355. (in Chinese). 
Li, H.X. (2011a). The case study of partenership beteen university and kindergarten to promote the teacher professional development. (Masteral Dissertation). Northwest Normal University, LanZhou, China. (in Chinese) Retrived from CN KI database.

Li, J. (2011b). Study on the university teacher professional development under professional learning community. Changsha: Hunan Agricultural University, 9. (in Chinese).

Li, M. (2008). Research on construction and operating model of excellent teaching team in university. (Masteral Dissertation). Nanjing University of Science and Technology, Nan Jing, China. (in Chinese) Retrieved from CNKI database.

Li, Y. (2016). The analysis of the model of teacher professional collabration in universities and local school research section. The Inservice Education And Training of School Teachers (2), 10-14. (in Chinese).

Lin, X. (2013). Collaboration of mathematics teachers in primary and secondary school under the new curriculum. Journal of Teaching and Management, 55-57. (in Chinese).

Lin, Y. (2007). The pathological phenomenon dialysis of teacher culture. Educational development research, 12. (in Chinese).

Little, J.W. (1990). The persistence of privacy: Autonomy and initiative in teachers' professional relations. Teachers College Record, 91(4), 509-536.

Littler, D., Leverick, F. \& Bruce, M. (1995). Factors Affecting the Process of Collaborative Product Development:A Study of UK Manufactures of Information and Communication Technology Products. Journal of Product Innovation Management, 12, 16-32.

Liu, L. (2011). Based on the development of teaching in English teachers' cooperative team. Journal of Teach, 41-42. (in Chinese).

Liu, L.M., \& Yang, N. (2017). The construction of college teachers' professional learning community based on cooperative culture. Teacher Educational Forum, 30(07), 5-9.

Lu, Y. (2007). A study of teachers' professional co-operation practice. (Masteral Dissertation). East China Normal University, Shanghai, China. (in Chinese) Retrieved from CNKI database.

Ministry of Education of the People's Republic of China. (2010). On deepening the basic education curriculum reform to further improve the quality of education (in Chinese). Retrieved from http://www.gov.cn/zwgk/2010-06/o2/content_1619006. htm.

Ministry of Education of The People's Republic of China. (2012). Professional standards for kindergarten teacher, primary teacher, secondary teacher (Trial). Retrieved from http://www.gov.cn/zwgk/2012-o9/14/content_2224534.htm.

Niu, L.H. (2014). The threshold and breakthrough of recognition - Some misunderstanding of teacher professional collaboration and its subsequent efforts. Journal of Northeast Normal University (Philosophy and Social Sciences), (1), 175-178. Retrieved from ProQuest D issertations \& Theses A\&I database. 
Sargent, T.C., \& E. Hannum. (2009). Doing More with Less: Teacher Professional Learning Communities in Resource-Constrained Primary Schools in Rural China.Journal of Teacher Education 6o (3), 258-276. Doi: 10.1177/0022487109337279.

Shen, J. (2015). Key elements and situation analysis of teacher community. Curriculum, Teaching material and Method, 35(4), 105-109. (in Chinese).

Tan, C. 2013. Learning from Shanghai: Lessons on Achieving Educational Success. Singapore: Springer. Doi: 10.1007/978-981-4021-87-6.

Thomas, G., \& Wineburg, S., \& Grossman, P. (1998). In the company of colleagues: An interim report of the development of a community teacher learners. Teaching and Teacher Education, (1), 21-32.

Van Maanen, J., \& Barley, S.R. (1984). Occupational communities: culture and control in organizations. La Revue Du Praticien, 15(29), 38-53.

Vangrieken, K., Dochy, F., Raes, E., \& Kyndt, E. (2015). Teacher collaboration: A systematic review. Educational Research Review, 15, 17-40.

Villegas-Reimers, E. (2003). Teacher Professional Development: An International Review of the Literature. Paris: UNESCO.

Waller, W. (1932). The sociology of teaching. UK: Books on Demand.

Wang, B.Y. (2013). The problem analysis and countermeasure suggestion of university teacher collaboration. Journal of Linyi University, (2), 13-16.

Wang, H. (2016). The analysis of operating elements based on regional collaboration in teacher education community : A case study of "Outstanding teacher study project" in primay and middle school teachers from Beijing, Suzhou, Guangdong, Zhejinag. The Inservice Education and Training of School Teachers, 363, 6-10. (in Chinese).

Wang, T. (2014). "Contrived Collegiality versus Genuine Collegiality: Demystifying Professional Learning Communities in Chinese Schools." Compare, 45 (6), 908-930. doi: 10.1080/03057925.2014.952953.

Wei, L.R. (2014). Expert teacher workshop led me to grow. Henan Education (Basic Edition), (12), 27.

Wen, Q.F. \& Ren, Q.M. (2010). The characteristics, trends, problems and countermeasures of professional development research - Analysis of related literatures from 1999 to 2009 in China. The Journal of Foreign Languages in China, (4), 77-83.

Westheimer, G. (2008). Illusions in the spatial sense of the eye: Geometrical-optical illusions and the neural representation of space. Vision Research, 48, 2128-2142. doi: 10. 1016/j. visres.2008.05.016.

$\mathrm{Wu}, \mathrm{J}$. (2009). Based on the cooperation of classroom observation: The perspective of the educational research group. Modern Science of Education (2), 23-27. (in Chinese).

Wu, W. (2012). An epistemology analysis based on the cooperation between a young professional and fresh teachers. Studies in Preschool Education (2), 44-48. (in Chinese). 
Xia, B. (2015). The construction of teachers' professional development community in Chinese-foreign collabration in running schools. Higher Education Exploration (5), 113-116. (in Chinese).

Xin, X., \& Wang, D. (2011). University-kindergarten partnership: An effective approach to raising preschool education quality in western areas: Refer experiences of school improvement project for early childhood education of the Chinese University of Hong Kong. Early Childhood Education (Educational Sciences) (11), 17-21. (in Chinese).

Yang, W.M. (2013). Professional learning community: origin, connotation and operation strategy. Higher Education Exploration, (4), 17-21.

Ye, L., \& Si, H. (2017). Based on "PET" collabration mode of primary and secondary school teachers' professional development research and practice. The Inservice Education and Training of School Teachers (2), 09-12.

Yu, C. (2007). A study of the working style difficult position and relevant strategies for the teacher's cooperation team. (Masteral Dissertation). East China Normal University, Shanghai, China. (in Chinese) Retrieved from CNKI database.

Zhang, H., \& Zhang, J. (2011). On the primary and high school teacher cooperation over the past thirty years. Journal of Hebei Normal University (Educational Science Edition), 13(4), 22-26. (in Chinese).

Zhang, Z. (2014). Development and features of teachers' collaboration in teaching and research abroad. Primary \& Secondary Schooling Abroad (8), 48-52. (in Chinese).

Zhang, Z., \& Peng, S. (2012). The three implications for teacher education community. Educational Research (11), 93-97. (in Chinese).

Zhang, Z., \& Zhao, Q. (2012). Teacher education community: Content, meaning and strategy. Journal of Capital Normal University (Social Sciences Edition) (6), 132-135. (in Chinese).

Zhou, F., Liang, A., \& Wang, L. (2016). The current situation, problems and promotion mechanism for teachers team of primary and secondary school. Theory and Practice of Education, 36(10), 44-47. (in Chinese).

Zhu, Y. (2014). A research on co-teaching partnership between Chinese and foreign teachers overseas. Language Education and Research (36-44). (in Chinese). 